\title{
(6) OPEN ACCESS \\ The UK National Neonatal Research Database: using neonatal data for research, quality improvement and more
}

\section{Gale, ${ }^{1}$ I Morris, ${ }^{2}$ on behalf of the Neonatal Data Analysis Unit (NDAU) Steering Board}

${ }^{1}$ Imperial Clinical Trials Unit,
Imperial College London,
London, UK
${ }^{2}$ Neonatal unit, University
Hospital Wales, Cardiff, UK

Correspondence to

Dr C Gale, Neonatal Medicine, Imperial College London, Chelsea and Westminster Campus, 369 Fulham Road, London SW10 9NH, UK; christopher.gale@imperial.ac.uk

Received 9 December 2015 Revised 29 January 2016 Accepted 22 February 2016 Published Online First 11 March 2016

\section{CrossMark}

To cite: Gale C, Morris I, on behalf of the Neonatal Data

Analysis Unit (NDAU) Steering Board. Arch Dis Child Educ

Pract Ed 2016;101:216-218.

\section{INTRODUCTION}

Electronic data are increasingly recorded in clinical practice. Just as advances in genetics have gradually led to clinical benefit ${ }^{1}$ so too are 'big data' bringing tangible advances to patient care. ${ }^{2}$

The UK has a long history of using electronic neonatal data for research and is now in the enviable position of having electronic patient data on all admissions to National Health Service (NHS) neonatal units in England, Wales and Scotland. This national resource, the National Neonatal Research Database (NNRD), is available for research, audit, benchmarking and quality improvement. Here, we provide an overview of how data entered into an electronic system (Badger.net; Clevermed Ltd) as a component of day-to-day care, are used to form the NNRD and how this can be used by health professionals.

\section{A BRIEF HISTORY OF NEONATAL DATABASES}

For over 25 years, neonatal data have been collected in regional databases such as The Neonatal Survey. The availability of national neonatal data is, however, a relatively recent phenomenon in the UK and internationally. In the UK the use of electronic patient records shared across neonatal units began in 2004 as a regional initiative. This platform, Badger.net, subsequently expanded nationwide; it is now used by many neonatal units to plan services and record activity for payment by NHS England.

In 2007, the Neonatal Data Analysis Unit (NDAU) was established at the Chelsea and Westminster Hospital campus of Imperial College London to improve the quality of electronic clinical data and promote their use to support neonatal services and facilitate research.
Data entered onto the Badger.net system are extracted at intervals, undergo quality assurance procedures, are anonymised and entered into the NNRD (box 1).

\section{HOW THE NDAU AND THE NNRD WORK}

All neonatal units that contribute data to the NNRD form the UK Neonatal Collaborative (currently 100\% of neonatal units in England, Wales and Scotland). NNRD data originate from information entered by clinicians (usually trainees) and nursing staff onto the Bager.net platform at the point of care. Approximately 400 predefined data items, the Neonatal Data Set, are extracted quarterly from these electronic patient records to form the NNRD (figure 1). The Neonatal Data Set is an approved NHS Information Standard hence any neonatal electronic system must be able to capture these items. To date the NNRD holds data on approximately 500000 patients with 20000 added quarterly. Data include ICD10 codes and mapping to Systematized Nomenclature of Medicine-Clinical Terms (SNOMED-CT) ${ }^{3}$ is underway.

The NNRD is a national Research Ethics Committee approved database; Caldicott Guardians and Neonatal Lead Clinicians of all contributing Trusts have approved the use of the NNRD for health services evaluations and authorised research. Parents are informed about the NNRD and can opt out at any time. Neonatal electronic patient record data can be used by health professionals in a variety of ways.

\section{USING NEONATAL DATA LOCALLY}

The electronic platform (Badger.net) provides ready access to local data by local clinicians. These may be used for audits, 
Box 1 Data management services performed by the Neonatal Data Analysis Unit (NDAU) on Badger. net data prior to forming the National Neonatal Research Database (NNRD)

- Separate patient identifiers into a discrete relational database

- Merge data packets to create a single file for each patient for each neonatal unit episode

- Link patient episodes across neonatal units (transfers) to create single linked episode file for each patient to discharge or death

- Identify and flag missing, inconsistent and out-of-range data for feedback to Neonatal Units

- Link NNRD to Hospital Episode Statistics and Office for National Statistics data

service evaluations and quality improvement projects; examples include:

1. Identification of procedures (eg, percutaneous central lines).

2. Identification of complications (eg, blood stream infections).

3. Describing resource usage (eg, duration of stay).

4. Production of activity reports.

Many neonatal units have staff able to assist in using the electronic platform in this way; additionally Clevermed (the commercial provider of the Badger. net platform) can provide support: http://www. clevermed.com.

\section{USING THE NNRD}

The NNRD is a national resource to support regional and national quality improvement, audit, benchmarking and research. Data held in the NNRD cover the whole clinical stay for each infant, linking all episodes of care. The NDAU can provide data extraction, analysis and statistical support; however, because the NDAU receives no core funding to maintain the NNRD, a charge is necessary to cover data transfer,

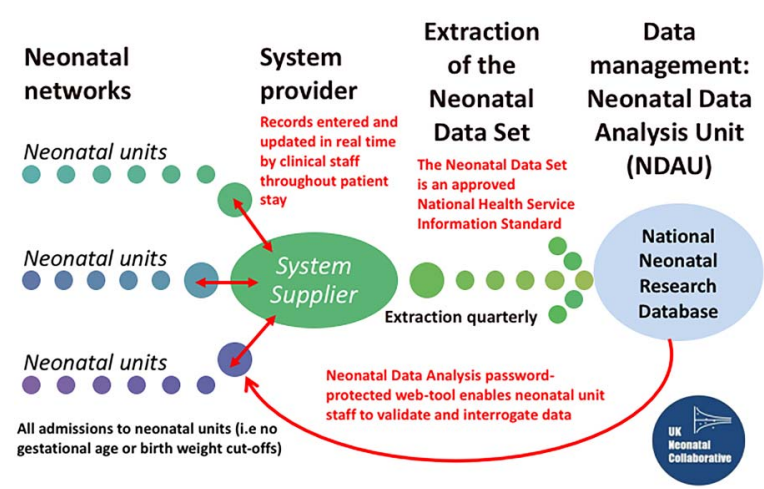

Figure 1 Data flows to the National Neonatal Research Database. (Courtesy of Mr Eugene Statnikov and Professor Neena Modi). extraction, cleaning, storage and any analyses requested. Examples of NNRD data use include:

1. Evaluating the national reorganisation of neonatal services into managed clinical networks. ${ }^{4}$

2. Describing longitudinal growth among preterm infants. ${ }^{5}$

3. Evaluating the impact of a regional quality improvement project. ${ }^{6}$

Further work seeks to establish the use of the NNRD for randomised clinical trials. ${ }^{7}$

If clinicians wish to use NNRD data for a regional, national or international project or in research, the NDAU can be contacted at https://www1.imperial.ac. $\mathrm{uk} /$ departmentofmedicine/divisions/infectiousdiseases/ paediatrics/neonatalmedicine/ndau/. Costs of using the NNRD can be built into funding applications so we advise contacting the NDAU early in the development of a proposed study.

\section{SUMMARY}

Data entered by UK neonatal professionals into the Badger.net platform are used to form a unique resource, the NNRD. As a result of the diligence taken by the numerous (often trainee) doctors and nurses who enter data every day, the NNRD forms one of the most detailed, accurate and complete population level neonatal datasets worldwide. The NNRD can be used to support local, regional, national and international work ranging from audit to observational and interventional research. Paediatricians and neonatologists are ideally placed to identify research questions with the potential to improve neonatal care; the NDAU and the NNRD can support health professionals in undertaking such initiatives.

Collaborators Members of the NDAU steering board are Zoe Chivers (representing the national charity Bliss), Kate Costeloe (cochair), Jacki Dopran, Jon Dorling (representing the Neonatal Clinical Reference Group), Chris Gale (trainee representative),

Rebecca Lemin (representing Neonatal Network Managers), Azeem Majeed, Gopi Menon (representing the British

Association of Perinatal Medicine), Neena Modi (Director), Ian Morris (trainee representative), Vimal Vasu (representing the

United Kingdom Neonatal Collaborative) and Andrew Wilkinson (cochair; representing the Royal College of Paediatrics and Child Health National Neonatal Audit Programme).

Contributors CG and IM conceived, drafted the first draft and subsequently revised this manuscript. All authors were involved in conception and subsequent revisions of the manuscript.

Funding CG is supported by an Academy of Medical Sciences Starter Grant for Clinical Lecturers, AMS-SGCL10 (supported by the Medical Research Council, Wellcome Trust, British Heart Foundation, Arthritis Research UK, Prostate Cancer UK and The Royal College of Physicians) and a National Institute of Health Research (NIHR) Clinical Trials Fellowship, NIHRCTF-2014-03-02.

Competing interests CG and IM are voluntary, unremunerated members of the NDAU Steering Board. The NDAU receives no core funding and is supported by grants and donations, and through fees for commissioned services.

Provenance and peer review Commissioned; externally peer reviewed. 
Open Access This is an Open Access article distributed in accordance with the terms of the Creative Commons Attribution (CC BY 4.0) license, which permits others to distribute, remix, adapt and build upon this work, for commercial use, provided the original work is properly cited. See: http://creativecommons.org/licenses/by/4.0/

\section{REFERENCES}

1 Alton EW, Armstrong DK, Ashby D, et al. Repeated nebulisation of non-viral CFTR gene therapy in patients with cystic fibrosis: a randomised, double-blind, placebo-controlled, phase 2b trial. Lancet Respir Med 2015;3:684-91.

2 Fröbert O, Lagerqvist B, Olivecrona GK, et al. Thrombus aspiration during ST-segment elevation myocardial infarction. N Engl J Med 2013;369:1587-97.

3 Spencer A, Horridge K, Downs D. Empowering clinical data collection at the point of care. Arch Dis Child 2015;100:815-17.
4 Gale C, Santhakumaran S, Nagarajan S, et al. Impact of managed clinical networks on NHS specialist neonatal services in England: population based study. BMJ 2012;344: e2105.

5 Cole TJ, Statnikov Y, Santhakumaran S, et al. Birth weight and longitudinal growth in infants born below 32 weeks' gestation: a UK population study. Arch Dis Child Fetal Neonatal Ed 2014;99:F34-40.

6 Battersby C, Santhakumaran S, Upton M, et al. The impact of a regional care bundle on maternal breast milk use in preterm infants: outcomes of the East of England quality improvement programme. Arch Dis Child Fetal Neonatal Ed 2014;99: F395-401.

7 Gale C, Modi N, WHEAT trial development group. Neonatal randomised point-of-care trials are feasible and acceptable in the UK: results from two national surveys. Arch Dis Child Fetal Neonatal Ed 2016;101:86-7. 